УДК 316.334 .22

$10.17213 / 2075-2067-2021-3-95-101$

\title{
ПРОФЕССИОНАЛЬНОЕ СТАНОВЛЕНИЕ МЕДИКОВ В УСЛОВИЯХ ПАНДЕМИИ КОРОНАВИРУСА (ПО МАТЕРИАЛАМ ГЛУБИННЫХ ИНТЕРВЬЮ) ${ }^{1}$
}

\author{
(С) 2021 г. А. И. Черевкова
}

\section{Южниый федеральный университет, г. Ростов-на-Дону, Россия}

Цель исследования состоит в соииологическом измерении социального самочувствия медиков, профессиональное становление которых проходит на фоне пандемии коронавируса и вызванных ей институцчиональных трансформаций сферы здравоохранения.

Методологическую базу составляет субъективистский подход к сочиальному самочувствию, трактующий его как эмоционально-оценочное восприятие своей настоящей жизнедеятельности в контексте прошлого, настоящего и ожидаемого будущего. В качестве критериев его сочиологического измерения выбраны показатели, предложенные О.Н. Суняйкиной.

Эмпирической базой работы выступают проведенные в период с октября 2020 2. по февраль 2021 г. 40 глубинных интервью с врачами и средним медперсоналом, работающуим в государственных учреждениях здравоохранения Ростовской области.

Результаты исследования. Пандемия оказала положительное влияние на сочиальное самочувствие медиков, чьим первым местом работы стали моноинфекционные госпитали: они смогли, хоть и временно, улучшить свое сочииально-экономическое положение, получить уникальный опыт работы, ощутили повышение престижа своей профессии. Медики, начавшие работать в период пандемии в учреждениях, не перепрофилированных для оказания медицинской помощии пациентам с коронавирусной инфекцией, своими доходами и условиями работы не удовлетворены. Независимо от места работы они ориентированы на дальнейшее профессиональное развитие, однако испытывают беспокойство по поводу успешного трудоустройства и возможности финансово обеспечить свою семью.

Перспективу исследования составляет проведение массового анкетного опроса с иелью измерения сочиального самочувствия медицинского профессионального сообщества Ростовской области на групповом и институциональном уровне.

Ключевые слова: профессиональное становление; сочиальное самочувствие; медицинское сообщество; студенты медицинских вузов; ординаторы; пандемия коронавируса; здравоохранение; инфекиионный госпиталь; Ростовская область.

1 Исследование выполнено при финансовой поддержке РФФИ в рамках научного проекта №20-04-60466 «Социальное самочувствие профессионального медицинского сообщества в сложной эпидемиологической ситуации». 


\section{PROFESSIONAL BECOMING OF MEDICS \\ IN THE CONTEXT OF THE CORONAVIRUS PANDEMIC (BASED ON IN-DEPTH INTERVIEWS)}

\section{(C) 2021 A. I. Cherevkova}

\section{Southern Federal University, Rostov-on-Don, Russia}

The purpose of the study is to provide a sociological measurement of the social well-being of medics whose professional development takes place during the coronavirus pandemic and institutional transformations in the healthcare.

The methodological basis of the research is the subjectivist approach to social well-being, which interprets it as an emotional and evaluative perception of one's present life activity in the context of the past, present and expected future. The indicators proposed by $O$. N. Sunyaikina were chosen as the criteria for its sociological measurement.

The empirical basis of the work is 40 in-depth interviews conducted in the period from October 2020 to February 2021 with doctors and secondary medical personnel working in public health institutions of the Rostov region.

The results of the study. The pandemic has had a positive impact on the social well-being of doctors, whose first place of work was infectious diseases hospitals: they temporarily improved their socio-economic situation, gained a unique work experience, and experienced an increase in the prestige of their profession. Medics who started working during the pandemic in institutions that were not converted to provide medical care to patients with coronavirus infection are not satisfied with their income and working conditions. Regardless of the place of work, young medics are focused on further professional development, but they are concerned about successful employment and the ability to financially support their family.

The prospect of the study is to conduct a mass questionnaire survey to measure the social wellbeing of the medical professional community of the Rostov region at the group and institutional level.

Key words: professional becoming; social well-being; medical community; medical students; interns; coronavirus pandemic; healthcare; infectious diseases hospital; Rostov region.

Введение. Пандемия коронавируса внесла кардинальные изменения в клиническую практику учреждений здравоохранения и потребовала мобилизации всех имеющихся ресурсов. В условиях значительно возросшего потока пациентов и перепрофилирования больниц под инфекционные госпитали на помощь были призваны студенты старших курсов и недавние выпускники медицинских вузов, ординаторы, не имевшие опыта работы до начала пандемии. По данным Минздрава, к концу 2020 г. для работы в «красных зонах» было привлечено более 20 тыс. медиков-студентов, которые занимают должности младшего и среднего медицинского персонала, врачей-стажеров и врачей-специалистов [1].
Кроме того, в условиях институциональных трансформаций сферы здравоохранения начинают трудовую деятельность и медикистуденты, работающие в учреждениях, не перепрофилированных на оказание помощи пациентам с коронавирусной инфекцией: поликлиниках, больницах, родильных домах.

В данной статье предлагается анализ социального самочувствия медиков, профессиональное становление которых проходит в условиях пандемии коронавируса. Социальное самочувствие в рамках субъективистской методологии понимается как эмоционально-оценочное восприятие представителями профессионального медицинского сообщества своей настоящей жизнедеятельности в контексте 
прошлого, настоящего и ожидаемого будущего $[2,3]$. По О.Н. Суняйкиной, интегральными критериями социального самочувствия являются: «1) уровень жизни: доход, материальное положение, обеспеченность, занятость и безработица, гарантированность социальной защиты; 2) эмоционально-психологическое состояние; 3) социальные самоощущения: идентификация, состояние комфортности, социальные ценности; 4) жизненные и адаптационные стратегии; 5) самооценка потенциала: профессионального, социального опыта, личностных качеств» [4, с. 98].

Эмпирической базой анализа социального самочувствия выступают результаты качественного исследования, проведенного социологами Южного федерального университета в период с октября 2020 г. по февраль 2021 г. Было проведено 40 глубинных интервью с врачами и средним медперсоналом, работающим в государственных учреждениях здравоохранения г. Ростове-на-Дону (далее по тексту — Рн/Д) и других населенных пунктах Ростовской области (далее - PO): Азове, Гуково, Сальске, Таганроге, Шахтах и др. В число информантов были включены как медики, не имеющие опыта работы до пандемии или работавшие на март 2020 г. менее 1 года, так и опытные медики, трудоустроенные в моноинфекционных госпиталях (далее - МИГ), инфекционных отделениях больниц, ковидных бригадах скорой помощи, а также не работающие с пациентами с коронавирусной инфекцией. Интервью проходили в очном и дистанционном формате по видеосвязи (Skype/WhatsApp/Zoom).

Анализ эмпирических материалов показал, что медики, профессиональное становление которых происходит в период пандемии, высоко либо нейтрально оценивают удовлетворенность своей жизнью в целом: Меня устраивает и мое семейное положение, и профессиональное. Там, где я сейчас прохожу практику, меня тоже все устраивает (врач МИГ, 24 г., жен., Рн/Д). Информанты, работающие в «красных зонах», отмечают, что выплаты стали хорошим подспорьем для улучшения социально-экономического положения: Уровень моей заработной плать увеличился, потому что я стала официально работать в ковидном госпитале. До этого я получала только стипендию ординатора, которая составляет приблизительно $8 \mathrm{mbl}$ сяч рублей, чуть меньше (врач МИГ, 25 лет, жен., Рн/Д). Дополнительные выплаты выступили важным фактором при принятии решения о работе с коронавирусной инфекцией, однако при этом медики понимают временный характер этой меры поддержки: Как только перестанут платить выплаты, я думаю, никто не будет работать в таких условиях. Мои коллеги жалуются, что у всех полно кредитов, ипотек, и только сейчас y них появилась возможность их закрыть (медсестра МИГ, 22 г., Рн/Д).

Медики, не работающие с коронавирусной инфекцией, в интервью рассказывали, что уровень их заработной платы на фоне пандемии временно снижался: Сначала он был нормальный, я получал столько же, сколько и до пандемии, а затем он уменьиился. Вот. Были несколько нюансов, не до конца понятных, связанных с управлением, но это отдельный вопрос. Потом постепенно выровнялась, и сейчас, и последние месяца 3-4 у меня уровень, который был до пандемии (медбрат в роддоме, 22 г., Рн/Д). В отличие от врачей и медсестер, работающих в «красных зонах», они не удовлетворены уровнем оплаты труда, и особенно это характерно для медиков, работающих в небольших городах и сельской местности Ростовской области: Зарплата врачей несоизмерима с их трудом. Я вижу, как работает участковый врач, какая у него нагрузка, сколько работают медсестры. Те деньги, которые они получают, это вообще не оплата их труда. Своей оплатой я тоже не удовлетворена (медсестра в детской поликлинике, 22 г., РО).

Работающие медики-студенты и ординаторы отмечают, что удовлетворены тем, как питаются и одеваются, однако жилищные условия остаются проблемным вопросом, который информантам еще предстоит решать. Даже с учетом выплат они не могут позволить себе покупку собственного жилья: У меня нет возможности приобрести самостоятельно жилье или снять отдельное от родителей жилье, сейчас я полностью завишу от них. И даже с моим новым местом работы, с новой зарплатой у меня сейчас ещуе недостаточно накоплений (врач МИГ, 25 лет, жен., Рн/Д). Молодые специалисты склонны рассчитывать в этом вопросе на свои силы 
и помощь родителей: На самом деле рассчитывваю только на себя, нет таких мыслей, что мне кто-то должен в этом помочь или обязан (медсестра, 23 г., Рн/Д). Государственные программы эффективным механизмом поддержки информанты не считают, поскольку они предполагают работу в сельской местности (например, программа «Земский доктор»): После окончания университета можно уехать в сельскую местность, там будет предоставляться оплата и, по-моему, жилище, квартира там или дом. Я рассматривал такой вариант, но не хотелось бы. Все-таки хотелось бы в крупных городах устроиться (медбрат МИГ, 21 г., Рн/Д). О других программах поддержки медиков на национальном и региональном уровне информанты оказались не осведомлены.

Медики моноинфекционных госпиталей осознают временный характер своей занятости, некоторые информанты сообщали, что скоро лишатся работы: Уэсе намечаются сокрашения, и собственно, я под них попаду, потому что у нас у всех срочный контракт, всех предупредили, что как только пандемия закончится, нас всех будут увольнять. Не всех, но основную массу (медбрат МИГ, 21 г., Рн/Д). Будущий переход на «обычную» зарплату врача после высокооплачиваемой работы в госпитале также вызывает беспокойство: Сложно будет перейти с такой зарплаты на обычную работу. Конечно, там выплаты будут не такие. Вот в этом и есть загвоздочка, переход такой (врач МИГ, 24 г., жен., Рн/Д); Пандемия закончится, и нам снова понизят зарплаты в 10 раз. Уверенности в завтрашнем дне не хватает (медбрат МИГ, 20 лет, муж., Рн/Д).

Будущая карьера и сложности трудоустройства после окончания учебного заведения являются причиной переживаний для медиков, профессиональное становление которых происходит в период пандемии, независимо от места работы на момент проведения интервью: Сейчас все подпадают под сокращеение, закрываются госпитали, отделения, потому что резкий спад заболеваемости идет. Ещзе год назад такой конкуренции не было, можно было прийти в любую больницу и устроиться на работу (врач МИГ, 27 лет, муж., PО); Меня беспокоят финансовые риски, что я, получив профессию, не могу зарабатывать достаточно, чтобы обеспечить на 100\% семью (медсестра в детской поликлинике, 22 г., PO). Впрочем, кардинально менять сферу деятельности они не настроены и разочарования в выбранной профессии не испытывают: Нет, все-таки 6 лет в универе не для того я буду учиться, чтобь уйти куда-то ещзе. Я планирую оставаться здесь (медбрат МИГ, 21 г., $\mathrm{PH}_{\mathrm{H}} /$ Д).

Информанты из числа среднего медперсонала ориентированы на продолжение обучения в ординатуре, а врачи - на работу по специальности, получаемой в ординатуре, поэтому работа с ковид-пациентами является для них временной формой занятости, с которой они не связывают дальнейшую карьеру. Для среднего медицинского персонала работа в моноинфекционных госпиталях также является возможностью получить дополнительные баллы при поступлении в ординатуру, которое представляется непростым в условиях отсутствия бюджетных мест: Так получилось, что я попала сюда, и это может мне помочь поступить в ординатуру, дать дополнительные балльл. <..> Бюджетных мест сейчас как таковых нет, только иелевые и платныле. Сейчас все выпускники попьтаются получить целевое, поэтому будут некоторые сложности (медсестра МИГ, 22 г., $\mathrm{PH} / Д)$.

Вместе с тем материальная поддержка и баллы для поступления в ординатуру не являются единственными мотивами работы в «красных зонах» для молодых специалистов. Гуманистические мотивы, желание помогать людям оказались важны не только при выборе профессии, но и в момент принятия решения о работе в условиях повышенных рисков: Я хотела быть полезной обществу и выбрала профессию врача. По зову сердчуа (врач МИГ, 24 года, жен., Рн/Д). Далее о решении работать с ковид-пациентами информант говорит так: Если честно, это было очень легко, то есть я вообщуе не боялась этого, абсолютно, даже с неким интересом ила туда работать. Очень не хватало людей, поэтому на зов пошла. Другим важным мотивом выступает получение опыта работы в сложных условиях и причастность к глобальному уникальному событию: Это чтото новое, интересное. Не поймите меня неправильно, я против того, чтобы люди стра- 
дали, но я рад все-таки, что побыл в «красной зоне», посмотрел на все, как лечить это. В плане образования и саморазвития мне это очень даже понравилось (врач МИГ, 27 лет, муж., РО); Это все-таки такое событие, которое не повторяется. <...> Я могу поставить галочку в своей биографии, что я была причастна к этой работе (врач МИГ, 25 лет, жен., Рн/Д).

Риски заражения коронавирусной инфекцией на рабочем месте медиками МИГ в интервью не акцентировались, и в большей степени информанты при принятии решения о работе беспокоились о том, что подвергают опасности свою семью. Чтобы обезопасить членов семьи, информанты снимают отдельное жилье на период работы и ограничивают контакты с родными: Родители в возрасте, $и$ я переживала, что могу привезти инфекциию домой. Я в отдельной квартире жсла, чтобы ездить работать отдельно и не видеть родителей. Я очень долго родителей не видела (врач МИГ, 24 г., жен., Рн/Д). На рабочем месте работники госпиталей чувствуют себя безопасно, поскольку на момент проведения интервью уже были полностью обеспечены средствами индивидуальной защиты: СИЗы в достаточном количестве: респираторы, скафандрыл, шапочки, очки. С этим прямо иикарно все. $<\ldots>$ Костюмы всегда абсолютно чистые, не было такого, что скомкали, положили, кинули куда-нибудь, все разграничено (врач МИГ, 27 лет, муж., РО).

Об опасности заражения в интервью говорили медики, не работающие напрямую с коронавирусными больными и не обеспеченные средствами защиты: Не учитывается то, что коронавирусные больные могут прийти в поликлинику, пройти по коридору, сходить в один, другой кабинет. Почему-то вот это не считается за контакт медичинского работника с больным. И это я считаю главной несправедливостью в данный момент (медсестра детской поликлиники, 22 г., РО).

Медики, чей профессиональный старт произошел в период пандемии, опыт работы в моноинфекционных госпиталях оценивают как «боевое крещение», «самопожертвование», «бой», работу в «огне», на которую они пришли «как зеленые студенты» и где «трудились не покладая рук», работая с па- циентами, находящимися «на грани жизни и смерти», а затем «с чувством выполненного долга» шли домой. Работа в госпитале расценивается как закалка характера: Пока молодой, энергичный, можно в таких условиях поработать. У меня такое представление, что если пройти через огонь и воду, то другие условия тебе уже будут казаться детскими (медбрат МИГ, 21 г., Рн/Д).

В сложных условиях работы медики испытывали усталость: Дикая усталость, было не до смеха, не до радости, просто хотелось отдыхать (врач МИГ, 24 г., жен., Рн/Д), однако истощение и симптомы профессионального выгорания информантами не фиксировались. В качестве потенциального фактора выгорания в условиях пандемии один из информантов отметил непредсказуемость течения болезни, малоизученность инфекции: Частая смерть пацчентов, которая от тебя никоим образом не зависит. <..> В связи с этим возможен элемент профессионального выгорания, плюс на фоне постоянной усталости, отсутствия выходных (врач МИГ, 25 лет, жен., Рн/Д).

Работая в госпиталях, медики-студенты и ординаторы почувствовали уважение к своей профессии, как со стороны пациентов, так и со стороны родственников и друзей: Со стороны обычных людей идет волна благодарности, внимания, которого раньше не было. Люди острее понимают, что находятся в опасности, имеют дело с болезнью, от которой могут умереть, и начинают больие иенить труд медиков (врач МИГ, 25 лет, жен., Рн/Д); Друзья поддерживали, какая-то гордость была за меня (врач МИГ, 24 г., жен., Рн/Д).

Еще одним фактором позитивной оценки опыта работы в моноинфекционных госпиталях выступила атмосфера взаимопомощи в трудовом коллективе, ощущение сплоченности перед общей проблемой: Это лучший коллектив, и, наверное, такого места работы у меня уже не будет. Молодой коллектив, мы, скажем так, были все на равных, все дружелюбные, очень хорочие ребята, правда, простые, без зависти. Я не знаю, как объяснить. Когда мы уходили, мы плакали (врач МИГ, 24 г., жен., Рн/Д). Пандемия стала фактором активизации наставничества, передачи навыков практической работы от опытных 
врачей молодым: Я боялась, что коллектив будет плохой, тем более, я ещуе ничего не умела. Но меня всему научили, очень хорочо относились ко мне даже поначалу, а сейчас относятся ко мне на равных. Если я чего-то не знаю или не умею, мне всегда подскажут (медсестра МИГ, 22 г., Рн/Д). В то же время начинающие специалисты, не работающие с коронавирусной инфекцией, испытывают трудности при вхождении в устоявшиеся коллективы поликлиник и больниц: Скажем так, каждый сам за себя, сам по себе (медсестра, 23 г., Рн/Д); Работа в коллективе дается мне не очень просто. Новеньких людей воспринимают так, будто ты совсем молодой и совсем ничего не умеешь (медсестра в детской поликлинике, 22 г., РО).

Общим для всех студентов и ординаторов изменением в жизни в период пандемии стал переход на дистанционный формат обучения. Отсутствие доступа в медучреждения в рамках практических занятий информантами оценивается негативно в перспективе профессионального развития: $\mathrm{Mbl}$ до сих пор полностью на дистанционном обучении, а в моей профессии невозможно получить знания без стационара, без паџиентов, без клиники (медсестра МИГ, 22 г., Рн/Д); С началом пандемии многие заведения закрылись, осталось все на уровне теории, а знания без практики ни к чему хорошему не приведут (медбрат в роддоме, 22 г., Рн/Д). Некоторые информанты видят в этом формате возможности для самообразования при наличии мотивации и самодисциплины: Не нужно тратить время на дорогу на пары, из-за этого освобождается довольно большой кусок времени, в который ты можешь либо работать, либо читать литературу. < ..> Если студент хочет слушать лекциию, он будет и в дистанционном формате ее слушать, а если не хочет, то даже если он будет сидеть перед преподавателем, никто его не сможет заставить и внушить ему это (медсестра в детской поликлинике, 22 г., РО).

Таким образом, пандемия оказала положительное влияние на социальное самочувствие медиков, первым местом работы которых стали моноинфекционные госпитали: они смогли, хоть и временно, улучшить свое социально-экономическое положение, получить уникальный опыт работы, ощутили по- вышение престижа своей профессии. Работа с пациентами с коронавирусной инфекцией дала быстрый профессиональный старт и способствовала развитию наставничества в условиях необходимости быстрой подготовки специалистов и мобилизации ресурсов. Медики, начавшие работать в период пандемии в учреждениях, не перепрофилированных для оказания медицинской помощи пациентам с коронавирусной инфекцией, своими доходами и условиями работы не удовлетворены, притом что также работают в ситуации повышенных эпидемиологических рисков. Независимо от места работы медики ориентированы на дальнейшее профессиональное развитие, однако испытывают беспокойство по поводу будущего трудоустройства и возможности финансово обеспечить свою семью.

\section{Литература}

1. «Это поможет мне в будущем»: студенты медицинских вузов о том, как на них сказалась работа в пандемию [Электронный pecypc] // RT на русском. - Режим доступа: https://russian.rt.com/russia/article/808749studenty-mediki-koronavirus.

2. Vyalykh N.A., Nor-Arevyan O. A., Posukhova O.Y., MosienkoO.S., CherevkovaA.I. Methodological matrix for sociological study of social well-being of the professional medical community during a complex epidemiological situation // Turismo: Estudos\&Práticas (UERN), Mossoró/RN, Caderno Suplementar 01, 2021.

3. Вялых Н. A. Факторы социального самочувствия профессионального медицинского сообщества в условиях пандемии нового коронавируса // Гуманитарий Юга России. 2021. - T. 10. — №1. - С. 102-110.

4. Суняйкина О.Н. Понятие «социальное самочувствие» в социологии // Вестник Мордовского университета. - 2011. - №3. C. 98-101.

\section{Referenses}

1. «Jeto pomozhet mne v budushhem»: studenty medicinskih vuzov o tom, kak na nih skazalas' rabota v pandemiju [«This will help me in the future»: students of medical universities about how they were affected by work in the pandemic] [Jelektronnyj resurs] // RT na russkom [RT in 
Russian]. — URL: https://russian.rt.com/russia/ article/808749-studenty-mediki-koronavirus.

2. Vyalykh N.A., Nor-Arevyan O. A., Posukhova O.Y., Mosienko O.S., Cherevkova A.I. Methodological matrix for sociological study of social well-being of the professional medical community during a complex epidemiological situation// Turismo: Estudos\&Práticas (UERN), Mossoró/ RN, Caderno Suplementar 01, 2021.

3. Vjalyh N.A. Faktory social'nogo samochuvstvija professional'nogo medicinskogo soo- bshhestva $\mathrm{v}$ uslovijah pandemii novogo koronavirusa [Factors of social well-being of the professional medical community in the conditions of the new coronavirus pandemic] // Gumanitarij Juga Rossii. — 2021. — Vol. 10. — №1. Pp. 102-110.

4. Sunjajkina O.N. Ponjatie «social'noe samochuvstvie» $\mathrm{V}$ sociologii [The concept of «social well-being» in sociology] // Vestnik Mordovskogo universiteta [Bulletin of the Mordovian University]. - 2011. — №3. - Pp. 98-101.

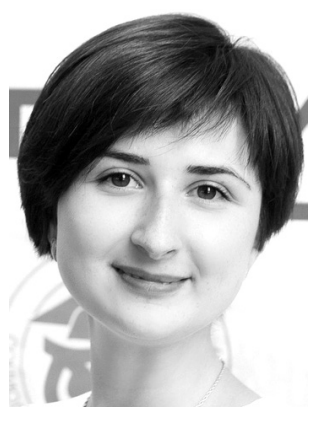

Черевкова Алена Игоревна - аспирант, стажер-исследователь Института социологии и регионоведения Южного федерального университета.

Cherevkova Alena Igorevna - Postgraduate Student, Research Assistant, Institute of Sociology and Regional Studies, Southern Federal University.

344006, г. Ростов-на-Дону, ул. Пушкинская, 160 160 Pushkinskaya st., 344006, Rostov-on-Don, Russia

E-mail: yaitskova_a@mail.ru 